\title{
Addition of Ester (Biodiesel) to Ethanol-Diesel Blend to Improve the Engine Performance and to Control the Emissions of Nitrous Oxides
}

\author{
Donepudi Jagadish", Ravi Kumar Puli, K. Madhu Murthy \\ Department of Mechanical Engineering, National Institute of Technology Warangal, 500604, Andhra Pradesh, India
}

\begin{abstract}
Usage of biofuels received much attention in the current situation of depleting fossil-fuel reserves and increased emission legislation. Many ideas have been implemented upon usage of biofuels for energy production to achieve low-emission levels. Internal combustion engines are the basic prime movers for power generation as well as for transportation purpose, which are basically run on fossil petroleum. Usage of eco-friendly fuels like ethanol and biodiesel as alternate fuels in engines attracted the attention of researchers. The present work envisages the effects of ester addition to the ethanol-diesel blends like E10, E20 and E30. The performance and emissions nature of ethanol-diesel blended fuel was observed using a single-cylinder, direct injection, constant speed diesel engine. Exhaust gas recirculation was adopted to control NOx emissions. Engine performance in terms of brake specific fuel consumption, and brake thermal efficiency is compared. The results showed that, the engine performance has been improved with an addition of ester to ethanol-diesel blend. Considerable reductions in emissions also been observed with the addition of ester, and using the EGR option reduction of NOx emissions was observed.
\end{abstract}

Keywords Engine Combustion, Ethanol, Ester, EGR, Nitrous Oxide Emissions

\section{Introduction}

Ethanol is one of the possible alternative fuels for partial replacement of mineral diesel in C.I engines. Many authors have reported ethanol-diesel blends up to $20 \%$ can very well be used in a present-day engine with minor adjustments. The common observations are the brake specific fuel consumption is slightly increased when higher concentrations of ethanol were used. The advantage of adding ethanol to diesel being the reductions in particulate matter (PM) emissions, and this may increase $\mathrm{CO}$ and total $\mathrm{HC}$ emissions. However, ethanol-diesel blends may be a viable alternate fuel concerning overall performance of the engine and emissions.

Many authors have reported that ethanol-diesel blends up to $20 \%$ can very well be used in the present day constant speed C.I engines without any modification. The common observations were the specific fuel consumption is slightly increased with higher concentrations of ethanol with no significant difference in the power produced and the thermal efficiency of the engine. Few authors reported that up to a $62 \%$ reduction in $\mathrm{CO}$ emission is possible with the use

* Corresponding author:

jagadish.donepudi@gmail.com (Donepudi Jagadish)

Published online at http://journal.sapub.org/ep

Copyright (C) 2011 Scientific \& Academic Publishing. All Rights Reserved of ethanol-diesel blends as compared to diesel alone, and NOx emissions also can be reduced[1]. Vegetable oil methyl ester being added to ethanol-diesel to prevent the separation of ethanol from diesel, and ethanol can be used up to $30 \%$ by volume in diesel with ester as an additive for best performance and low emissions[2].

Jincheng et al. has conducted experiments on a diesel engine with ethanol-diesel using an additive normal butanol. Thermal efficiency of the engine increased with the ethanol-diesel with a slight increase in fuel consumption, which is due to the less heating value of ethanol[3]. Hüseyin et al. investigated the effects of the blends of biodiesel and ethanol in a single cylinder four stroke direct injection diesel engine. The comparison has been made between B20 (20\% biodiesel and $80 \%$ diesel) and BE20 (20\% ethanol and $80 \%$ biodiesel) showing that the engine performance was significantly improved with BE20 than with B20, and all the engine emissions are considerably reduced[4].

Hwanam et al. has used biodiesel-diesel, ethanol-biodiesel-diesel blends in a common rail direct injection diesel engine and observed that overall performance was similar to the diesel fuel, and high fuel consumption was observed due to a decrease in heating value of biofuel blends resulted during mixing. The use of a both the blends reduced the total hydrocarbons, smoke and $\mathrm{CO}$ emissions but NOx emissions increased due to the increased oxygen content in the fuel[5]. 
The amount of energy released is dependent on the oxidation state of the carbons in the hydrocarbon which is related to the $\mathrm{H} / \mathrm{C}$ ratio. The more hydrogen per carbon the lower the oxidation state results in more energy that will be released during the oxidation reaction, thus the greater the $\mathrm{H} / \mathrm{C}$ ratio and better energy release on combustion. Ethanol generally has $\mathrm{H} / \mathrm{C}$ ratio nearly 3 promotes an improved combustion, and even the blends of ethanol-diesel may have similar effects. This may slightly increase the peak temperatures of combustion. Biodiesel usually expected to have higher $\mathrm{H} / \mathrm{C}$ ratios promotes better combustion, and the same time offers less CO and UBHC emissions[6]. This also offers the flexibility of usage of biodiesel-diesel, biodieselethanol-diesel blend fuels with options like EGR to control the NOx emissions, without much loss of engine mean torque.

The motive has been taken to observe the performance aspects of the engine fuelled with ethanol-ester-diesel with option EGR. Nevertheless, the EGR has been the most effective technique to reduce the NOx emissions from a diesel engine[7-19]. However, the reduction of NOx with EGR is limited due to adverse effects like increased particulates, increased UBHC, and severe effects on engine torque performance. The addition of ester to ethanol-diesel blends may permit to use high EGR rates while promising the considerable low levels of other emissions like PM and UBHC. Even to the present date similar kind of research is already available this work has been taken to support the concept of biofuels for the future energy needs.

\section{Details of Experimental Setup}

A naturally aspirated single cylinder diesel engine with a DC shunt dynamometer was used for experimentation. Slight modifications were made to the original engine set up to work with option cooled EGR. A heat exchanger was used to cool the exhaust gases while entering the inlet to maintain constant temperature $\left(34^{0} \mathrm{C}\right)$ throughout the experiment. Venturi arrangement was provided for effective mixing of exhaust gas and fresh air. Rotameters were used to measure the flow rates of inlet air and exhaust gas. Table 1 gives the details of the engine, and Table 2 provides the details of the exhaust gas analyzer with ranges and sensitivities. The schematic of experimental setup is shown in Figure 1.

Table 1. Details of Engine Test Setup.

\begin{tabular}{|c|c|}
\hline Manufacturer & $\begin{array}{c}\text { Kirloskar Oil Engines } \\
\text { Limited, India }\end{array}$ \\
\hline Engine Type & $\begin{array}{c}\text { Single cylinder, 4-stroke, naturally } \\
\text { aspirated, Direct injection, water cooled } \\
\text { C.I.Engine }\end{array}$ \\
\hline Rated Power & $3.7 \mathrm{~kW}$ at $1500 \mathrm{rpm}$ \\
\hline Bore/Stroke & $80 / 110(\mathrm{~mm})$ \\
\hline Compression ratio & 17.5 \\
\hline Start of Fuel Injection & $26^{0} \mathrm{BTDC}$ \\
\hline Nozzle Opening Pressure & $180 \mathrm{bar}$ \\
\hline
\end{tabular}

Table 2. Ranges and Sensitivities of Test Devices.

\begin{tabular}{|c|c|c|c|}
\hline Analyzer & Name & Range & Sensitivity \\
\hline $\mathrm{CO}$ & Kane-May Quintox & $0-10 \%$ & $0.01 \%$ \\
\hline $\mathrm{CO}_{2}$ & Kane-May Quintox & $0-10 \%$ & $0.01 \%$ \\
\hline $\mathrm{NO}$ & Kane-May Quintox & $0-5000 \mathrm{ppm}$ & $1 \mathrm{ppm}$ \\
\hline $\mathrm{HC}$ & Kane-May Quintox & $0-3000 \mathrm{ppm}$ & $1 \mathrm{ppm}$ \\
\hline Smoke meter & AVL 437 & $0-100 \%$ & $0.01 \%$ \\
\hline
\end{tabular}

\section{Experimental Methodology}

Biodiesel was prepared from palm stearin through the process of transesterfication using catalyst $\mathrm{NaOH}$. Palm stearin is the solid fraction obtained during the fraction of palm oil and is a co-product of palm olein. Small fractions of biodiesel were added to ethanol-diesel blends; the mixtures are named as E10B, E20B, and E30B. The properties of the base fuels are shown in Table 3. And the heating values of mixtures have been determined using a bomb calorimeter.

Table 3. Properties of Fuels.

\begin{tabular}{|c|c|c|c|}
\hline Property & Diesel & Ethanol & $\begin{array}{c}\text { Palm stearin methyl } \\
\text { ester }\end{array}$ \\
\hline Density $\left(\mathrm{kg} / \mathrm{m}^{3)}\right.$ & 840 & 789 & 874 \\
\hline Kinematic Viscosity $(\mathrm{cSt})$ & 2.44 & 1.52 & 4.76 \\
\hline Heating Value $(\mathrm{kJ} / \mathrm{kg})$ & 42,500 & 29700 & 39,900 \\
\hline Cloud Point, ${ }^{0} \mathrm{C}$ & 3 & -25 & 16 \\
\hline Pour Point, ${ }^{0} \mathrm{C}$ & -6 & -113 & 19 \\
\hline Flash Point, ${ }^{0} \mathrm{C}$ & 70 & 17 & 145 \\
\hline
\end{tabular}

Engine coolant temperature was kept constant at $55^{\circ} \mathrm{C}$ during entire engine operation, and inlet air temperature is maintained at $34^{\circ} \mathrm{C}$ during all the periods of operation. The tests were conducted on the engine without EGR and with EGR and the performance parameters like BSFC, BTE are compared. EGR rate is calculated using equation (1).

Volume flow rate of EGR

$\% \mathrm{EGR}=$---

Volume flow rate of inlet air charge

\section{Engine Performance}

The variation of BSFC with load is shown in Figure 2 and Figure 3. Under normal operation, and during exhaust gas recirculation, there is a rise in fuel consumption. Ethanol-ester-diesel blends with EGR showed less loss in the fuel economy, when compared with only diesel; and the values are comparable with no-EGR since the oxygenate quality of the ethanol compensates for the non-availability excess oxygen during EGR. Out of the selected blends E10B showed a good fuel economy even with higher EGR rates, which can be noticed from Figure 4. Fuel conversion capability seems to decrease with an increase in EGR percentage, nevertheless E10B showed better values of thermal 
efficiency and comparable with diesel. Whereas E20B, E30B showed higher values of BSFC when compared with diesel at all loads of engine operation.

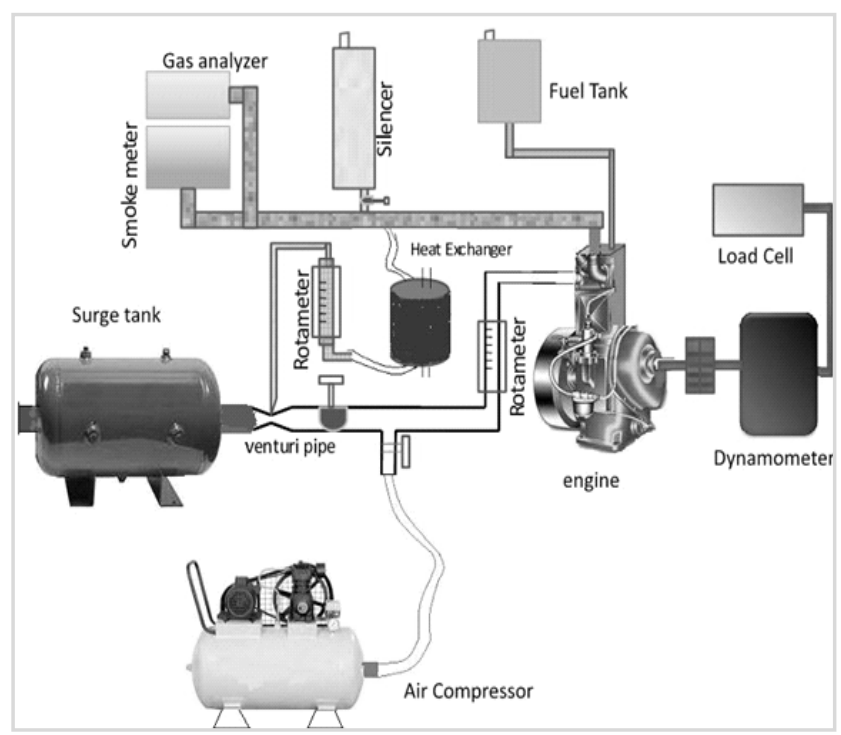

Figure 1. Schematic of Experimental Setup.

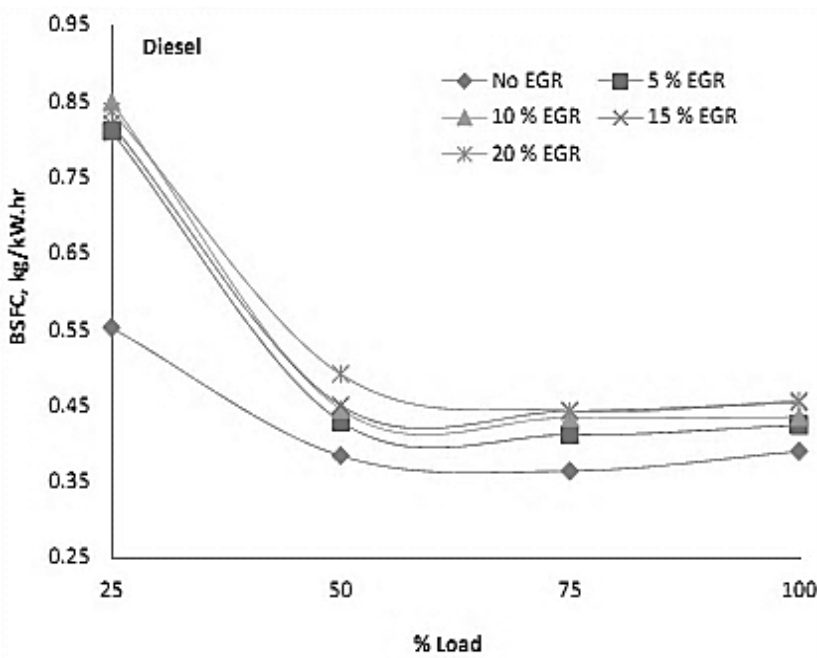

Figure 2. Variation of BSFC with Load at different EGR rates using fuel diesel.

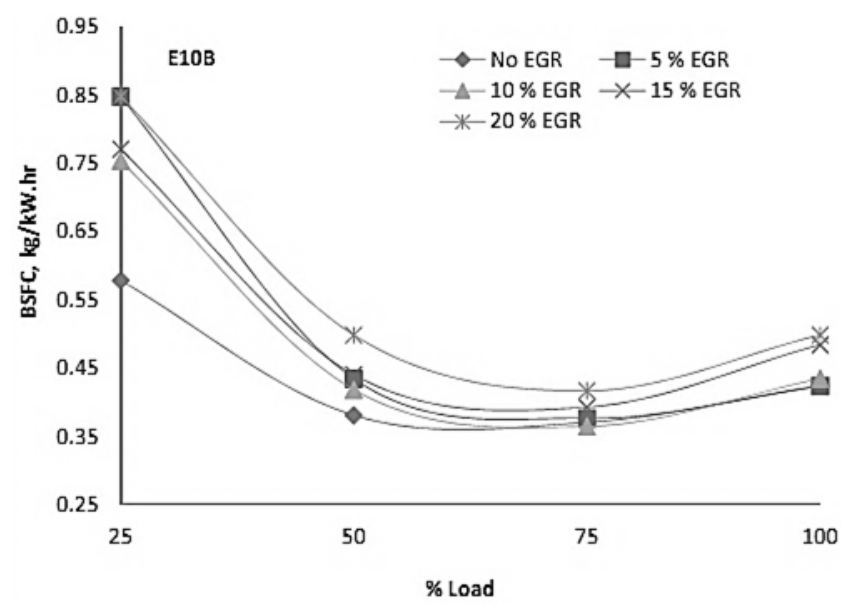

Figure 3. Variation of BSFC with load at different EGR rates using fuel E10B.

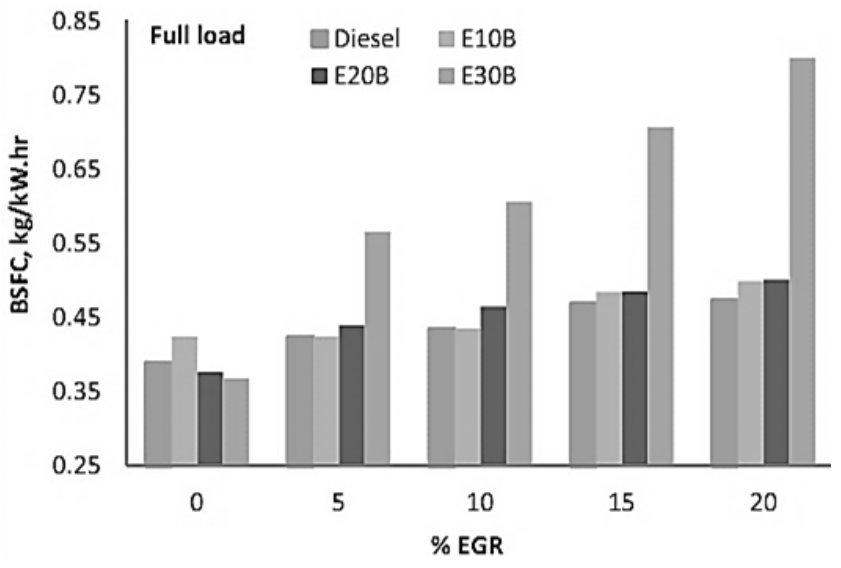

Figure 4. Comparison of BSFC with EGR rate for different fuels.

\section{Engine Emissions}

\subsection{Nitrous Oxides}

Nitrous oxide formation mainly depends on temperature, and a reduction in temperature can cause a reduction in NOx. With ethanol addition to diesel, the maximum temperatures of combustion may be raised, and the reasons can be attributed to a low burning rate of ethanol causing a rise in ignition delay causing a rise in the temperature of exhaust. However, with more ethanol concentrations, the peak temperatures of combustion may come down due to bulk quenching of the combustion products resulting in lower fuel-air ratios.

A major obstacle to the extensive application of diesel engines is their high levels of nitrogen oxides (NOx) and particulate matter emissions, both of which have negative effects on the environment. NOx contribute to ground level ozone $(\mathrm{smog})$ and acid rain with the consequent detrimental effects on human health. Introduction of the exhaust gas into the combustion chamber causes the dilution of the air charge by replacing $\mathrm{O}_{2}$ with the non-reacting $\mathrm{CO}_{2}$, as a consequence both the specific heat capacity of the in cylinder gas mixture, the peak flame temperatures of the cycle is reduced. As a result NOx emissions are reduced too, aided by the lower oxygen availability. However, a sharp increase in hydrocarbon emissions, particle size, and density was observed at higher EGR rates, while only slight changes were observed in conventional combustion parameters such as heat release and work $[7,8]$.

Having understood the advantages of adding ethanol to diesel, only fewer amounts of ethanol can be permitted to take the advantage of the oxygenate quality. The higher ethanol concentration in the diesel is limited due to increased fuel consumption. If high peak temperatures exist then EGR would be one technique to reduce NOx emissions.

A comparison is made for $\mathrm{NO}$ emissions with different EGR rates in the Figure 5, and it can be observed that an increased ethanol concentration showed considerable reduction of NO emissions. However, in the performance point 
increased ethanol concentration decreases the fuel economy, so $\mathrm{E} 10 \mathrm{~B}$ can be a best combination, and a low EGR rate $(<10 \%)$ can be effectively used to control NO emissions. It can be understood from the Figure 5, that the addition of ester to ethanol-diesel has considerable influence the combustion process resulting more reductions of NO emissions in comparison with only ethanol-diesel blends.

The EGR rate is limited due to increased fuel consumption, and UBHC with higher rates. The addition of ester to ethanol-diesel enhances the blend stability thus providing chances for efficient combustion resulting in the reduction of UBHC emissions, which are profound during the burning of ethanol-diesel blends. The addition of ester to ethanol diesel blends may increase the chances of low temperature combustion, contemplating the advantages of ethanol addition to diesel.

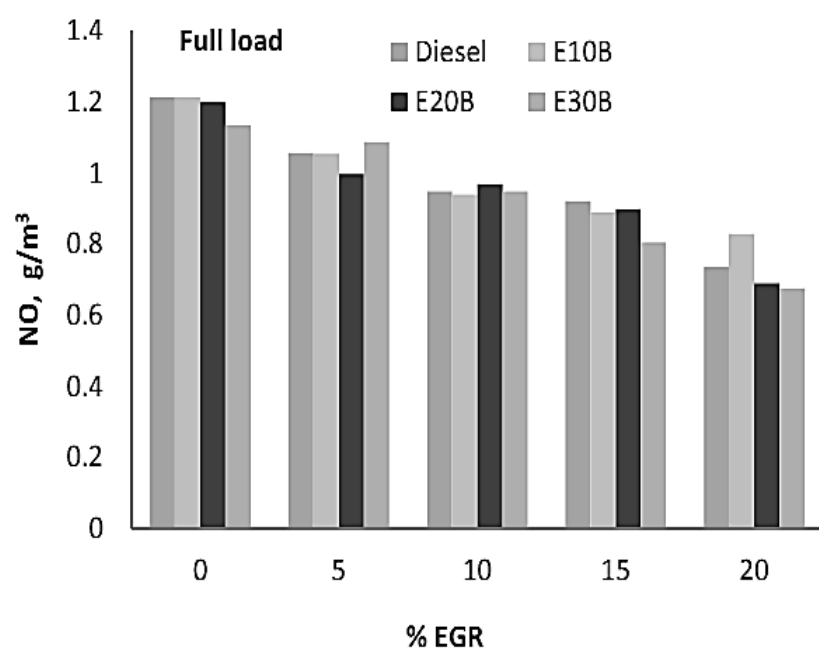

Figure 5. Comparison of Nitric oxide emissions under different EGR.

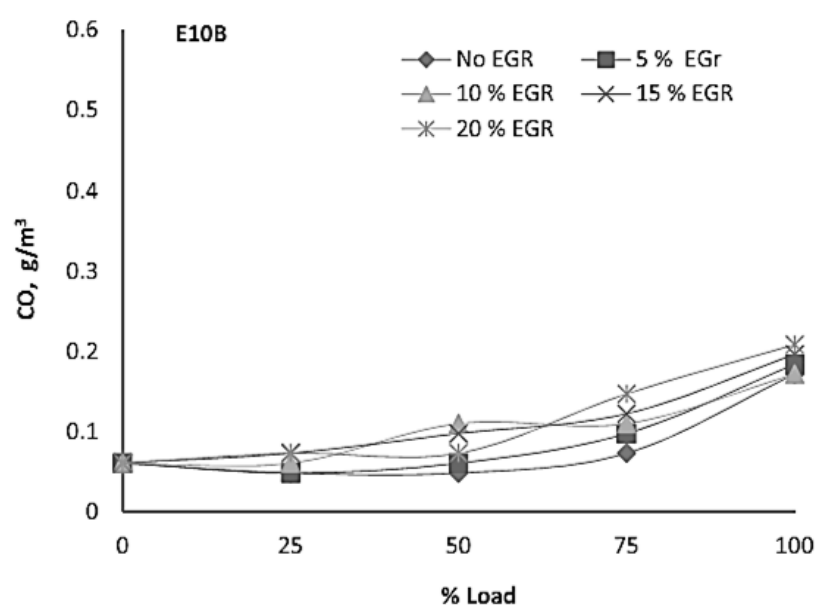

Figure 6. Variation of $\mathrm{CO}$ emissions with load and with different EGR rates for fuel E10B.

\subsection{Unburned Hydrocarbons}

Generally as the load on the engine increased, UBHC in the exhaust increases in many of the cases. It was observed during engine operation that as EGR percentage increases hydrocarbons in the exhaust increased. And further as the ethanol content in the diesel increased a rise in UBHC in the exhaust observed besides a drastic rise with higher EGR rates. However, less UBHC emissions during engine tests with ethanol-ester-diesel was observed.

\subsection{Carbon Monoxides}

Exhaust gas recirculation causes an increase in $\mathrm{CO}$ formation, and with high EGR rates, more $\mathrm{CO}$ emission was observed. Using the fuel diesel, a little rise in $\mathrm{CO}$ emissions was observed with a rise in EGR percentage, and also as the load on the engine increases $\mathrm{CO}$ formation increased. For ethanol-diesel blends drastic rise in $\mathrm{CO}$ formation was observed as shown in Figure 6, and the emissions were observed to be further aggravated with increased ethanol concentration. An outcome of less $\mathrm{CO}$ emissions was noticed with ester addition to ethanol-diesel blends.

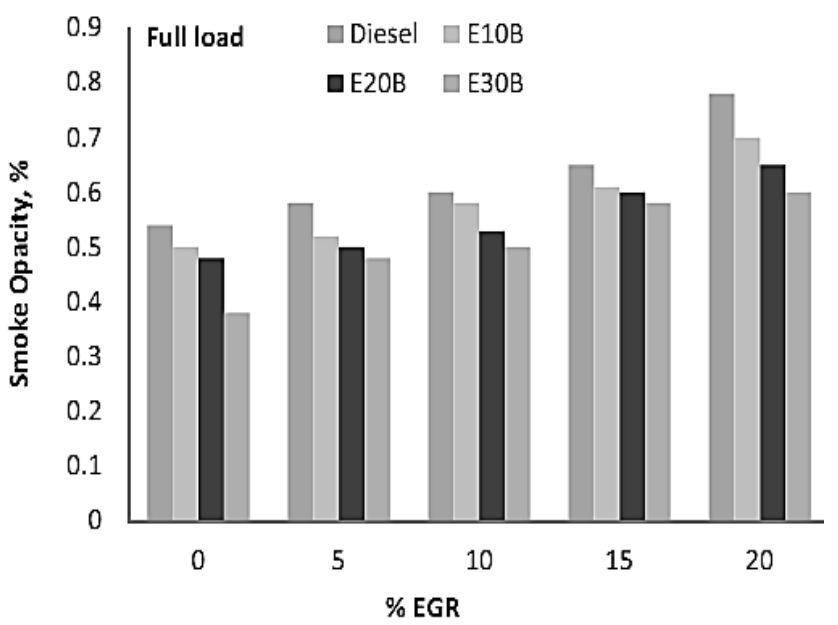

Figure 7. Comparison of smoke emissions for different EGR rates for different fuel blends

\subsection{Smoke Opacity}

As the load on the engine increased there is a little rise in smoke emissions from the engine exhaust. Exhaust gas recirculation aggravates the formation of smoke. From Figure 7 , the increased amount of ethanol in diesel resulted in less smoke in the exhaust, and the addition of ester slightly reduced these emissions.

\section{Conclusions}

Addition of esters to ethanol-diesel blends can cause an improvement in stability of the fuel blend, and during engine performance test some desirable effects like low NOx, low UBHC was noticed. The following overall conclusions may be drawn from the present work.

1. Lower fuel economy was observed with higher EGR rates (more than 10\%), and ethanol blending to diesel resulted in further increase in brake specific fuel consumption values.

2. Brake thermal efficiency slightly improved for ethanol-ester-diesel blends without EGR and reduced with higher EGR rates.

3. Ethanol content in the diesel helped in a reduction of 
NOx emissions and comparable better reductions were observed with addition of palm stearin methyl ester, which permits to use higher EGR rates. However, different feed stocks have different fatty acid composition even though many esters of different origin normally exhibit similar properties.

4. Common observations like increased hydrocarbon, carbon monoxide, and carbon dioxide emissions noticed with higher EGR rates while engine operated with ethanol-diesel. However, these concentrations are slightly reduced with ester addition.

5. Optimum value of EGR rate can be selected between $5-10 \%$ for ethanol-diesel fuel (E10B) with compromise between engine torque, fuel economy and $\mathrm{HC}, \mathrm{CO}$ emissions, and a rate of $10-15 \%$ can be safely used with ester addition since it minimizes the fuel losses.

\section{Abbreviations}

\begin{tabular}{|l|l|}
\hline BSFC & Brake Specific Fuel Consumption [kg/kW.hr] \\
BTDC & Before Top Dead Centre \\
BTE & Brake Thermal Efficiency [\%] \\
EGR & Exhaust Gas Recirculation \\
E10B & Blend of $10 \%$ ethanol,5\% ester,85\% diesel by volume \\
E20B & Blend of $20 \%$ ethanol,10\% ester,70\% diesel by volume \\
E30B & Blend of 30\% ethanol,10\% ester,60\% diesel by volume \\
NOx & Nitrous Oxides \\
UBHC & Unburned hydrocarbons \\
\hline
\end{tabular}

\section{ACKNOWLEDGEMENTS}

The authors are highly grateful to the staff I.C.Engines laboratory of mechanical engineering department, NITW for providing the test facilities and Chemical Engineering Department, NITW for providing the Gas analyzer and Laboratory facilities.

\section{REFERENCES}

[1] Agarwal, A. K., 2007, Biofuels (alcohols and biodiesel) applications as fuels for internal combustion engine., J. Progress in Energy and Combustion Science., 33, 233-271

[2] Hu, C., Shi-Jin, S., and Jian-Xin, W., 2007, Study on combustion characteristics and PM emission of diesel engines using ester-ethanol-diesel blended fuels., J. Proceedings of the Combustion Institute., 31, 2981-2989

[3] Jincheng, H., Yaodong, W., Shuangding, L., Anthony, P. R., Hongdong, Y., and Huifen, L., 2009, Experimental investigation on the performance and emissions of a diesel engine fuelled with ethanol-diesel blends., J. Applied Thermal Engineering., 29, 2484-2490

[4] Hyun, K. S., Hyun, G. R., and Chang, S. L., 2008, Spray and combustion characteristics of biodiesel diesel blended fuel in a direct injection common rail diesel engine., J. Engineering for Gas Turbine and Power., 130, 32801-32809
[5] Hwanam, K., and Byungchul, C., 2008, Effect of ethanol-diesel blend fuels on emission and particle size distribution in a common-rail direct injection diesel engine with warm-up catalytic converter., J. Renewable Energy., 33, $2222-2228$

[6] Nabi, N., Akhter, S., and Shahadat, M. Z., 2006, Improvement of engine emissions with conventional diesel fuel and diesel-biodiesel blends., J. Bio Resource Technology., 97, 372-378

[7] Sasaki, M., Kishi, Y., Hyuga, T., Okazaki, K., Tanaka, M., and Kurihara, I., "Effect of EGR on Diesel Engine Oil, and its Counter measures," SAE Paper No. 971695

[8] Kreso, A, M., Johnson, J, H., Gratz, L, D., Bagley, S, T., and Leddy, D, G., A Study of the Effects of Exhaust Gas Recirculation on Heavy Duty Diesel Engine Emissions., SAE Paper No.981422

[9] Hribernik, A., and Samec, N., 2004, Effect of Exhaust Gas Recirculation on Diesel Combustion., J.KONES Internal Combustion Engines.,11, No.1-2 http://www.ilot.edu.pl/KONES/2004/01/24.pdf

[10] Agrawal. A. K, Singh. S., Sinha. S., and Shukla. M. K., 2004, Effect of EGR on the exhaust gas temperature and exhaust opacity in compression ignition engines., Sadhana, 29(3), 275-284

[11] Haupt, D., Nord, K., Ahlvik, P., Egeback, K, E., Tingwall, B., Anderson, S., and Blomquist, M., Investigating the Potential to Obtain Low Emissions From a Diesel Engine Running on Ethanol and Equipped With EGR, Catalyst and DPF., SAE Paper No.2004-01-1884

[12] Pradeep, V., and Sharma, R, P., 2007, Use of Hot EGR for NOx control in a compression ignition engine fuelled with biodiesel from Jatropha oil., J. Renewable Energy., 32, 1136-1154

[13] Simoson, C., and Wagner,J., 2008, Effect of Cooled EGR on Small Displacement Diesel Engine: A Reduced Order Dynamic Modeling and Experimental Study., J. Energy Resource and Technology, 130, 11102-11111

[14] Saravanan, N., Nagarajan, G., Kalaiselvan, K, M and Dhanasekaran, C., 2008, An experimental Investigation of hydrogen as dual fuel for diesel engine system with Exhaust Gas Recirculation Technique., J. Renewable Energy, 33, 422-427.

[15] Rajan, K., and Senthil Kumar, K. R., 2009, Effect of exhaust gas recirculation (EGR) on the performance and emission characteristics of diesel engine with sunflower oil methyl ester. Jordan J. Mechanical and Industrial Engineering, 3(4), 306-311

[16] Donghui, Q., Michael, L., Yu, L., and Chia-fon, L., 2011, Effect of EGR and Injection Timing on Combustion and Emissions Characteristics of Split Injection Strategy DI-diesel Engine Fuelled with Biodiesel, Fuel, 90(5), 1884-1891

[17] Alain, M., and Xavier, T., 2011, "NOx and PM reduction on an Automotive Diesel Engine with Water-in-Diesel Emulsion and EGR: Experimental Study", Fuel, 90(11), 3179-3192 